\title{
Microbes and Health
}

ISSN: 2226-0153 (Print) 2305-3542 (Online)

http://journal.bsvmph.org/

Microbes and Health, June 2014, 3(1): 29-34.

\section{Growing Significance of Mycobacterium bovis in Human Health}

\author{
Mahendra Pal ${ }^{1}$, Nigusa Zenebe ${ }^{1}$ and Md. Tanvir Rahman ${ }^{2 *}$ \\ ${ }^{1}$ Department of Microbiology, Immunology and Public Health, College of Veterinary Medicine and Agriculture, Addis ababa University,P.B. No. 34, \\ Debre Zeit, Ethiopia \\ ${ }^{2}$ Department of Microbiology and Hygiene, Faculty of Veterinary Science, Bangladesh Agriculture University, Mymensingh -2202, Bangladesh.
}

*Corresponding author's email: tanvirahman@bau.edu.bd

\section{ABSTRACT}

Tuberculosis is one of the most wide spread highly infectious bacterial zoonotic diseases, and is responsible for high morbidity and mortality in the world particularly in the developing nations. Mycobacterium bovis and closely associated acid fast bacilli cause disease in humans and animals. Humans can be infected with M. bovis where cattle act as the principal reservoir. Air borne infections continue to occur among the persons working in the meat industry, slaughterhouses, and in persons living in close physical contact with infected animals.M. bovis infection is recognized as an occupational hazard to abattoir workers, livestock handlers and veterinarians. The main cause of concern related to $M$. bovis in industrialized counties are epizootics nature of the disease in domesticated and wild animals. In addition, latent infection in immigrants particularly in HIV infected patients are also a big issue in developed world, since those people could be the potential source of TB for other people. The reemergence of $M$. bovis infection in captive and free-ranging wild animals, with subsequent transmission to domestic animals, is of concern to livestock producers and regulatory officials. As wild animals represent major reservoir of tuberculosis bacilli, it is imperative to investigate the role of wild animals in transmission dynamics of $M$. bovis infection. Further studies on the molecular epidemiology and development of safe, cheap and potent drugs to mitigate tuberculosis in highly susceptible population particularly in HIV/AIDS patients is emphasized. In addition, multidisciplinary approaches such as 'One Health' that comprise professionals from medical science, veterinary medicine and wildlife etc. are essential to take measures to control this devastating bacterial zoonosis.

Key Words: HIV infection, Human health, Mycobacterium bovis, Route of Transmission, Source of Infection, Tuberculosis

Received: $10^{\text {th }}$ April, 2014. Accepted: $17^{\text {th }}$ July, 2014.

(C)2014 Microbes and Health. All rights reserved

\section{Introduction}

Tuberculosis (TB) is one of the oldest classic bacterial zoonoses, and is the leading cause of death due to single infectious agent among the adults in the world (Pal, 2005).Approximately, one-third of the world population is affected with TB (Pal, 2007). In 2012, about 8.6 million people fell ill with TB and 1.3 million died from TB (WHO, 2011).Among these population Africa displaying the highest annual risk of infection by TB, probably catalyzed by the AIDS/HIV pandemic (Corbett et al., 2003). Pulmonary TB occurs in 74-100\% of patients with HIV infection (Pal, 2005).

Mycobacterium bovis is the most universal pathogen amongst the Mycobacterium affecting many vertebrates including humans of all age groups although cattle, goats and pigs are found to be most susceptible (Radostits et at., 2000; Pal and Boru, 2012). Bovine tuberculosis (BTB) caused by M. bovis is a chronic infectious disease of animals characterized by the formation of granulomas in various organs, more significantly in the lungs, lymphnodes, intestine and in the kidneys (Pal and Boru, 2012).

BTB is one of the important diseasethat affects theproduction of animal. The human infections due to $M$. bovis have been reported from many countries of the world (O'Reilly and Daborn, 1995; Grane, 2001, Jou et al., 2008; Pal and Boru 2012). BTB is caused by M.bovis, which is genetically related to $M$. tuberculosis, the causative agent human tuberculosis (HTB). It could be speculated that BTB in humans is becoming increasingly important in developing countries as humans and animals are sharing the same micro-environment and dwellingpremises, especially in rural areas. Presently, the role of M.bovis as a cause of human tuberculosis is becoming significant especially in developing countries where there is a high prevalence of HIV/ADIS (Amanfu, 2006). The etiologic significance of M.bovis inHTBhas been undermined because of the following reason in most developing countries; bacteriological diagnosis of pulmonary tuberculosis usually relies on the acid-fast bacillus (AFB) smear examination due to limited laboratory resources. Use of culture is generally reserved for special situations, such as suspected treatment failure and relapses. In addition, culture is used in special surveys, including those undertaken to measure the prevalence of drug resistance (Sequeiraet al., 2005).

Infection of human due to M.bovis is mainly through drinking of raw milk and hence BTB due to $M$. bovis does occur in extra-pulmonary from particularly in cortically lmphadenitis form. However, M. bovis can also cause pulmonary TB (air borne infection) in patients, who live in contactto cattle, particularly in rural areas. Transmission of TB due to M. bovis or M .tuberculosis from HTB patients to cattle is also possible mainly due to contamination of pasture from urogenital TB cases in man (O'Reilly and Daborn., 1995). Ethiopia is a country where the impact of BTB is particularly important and it is one of the 13 th country singled out by (WHO, 1997) as a home for $75 \%$ of the world's TB cases. TB is one of the top three in Africa by the number of TB patients (Dye et al., 1999). However, there are no records of nationwide distribution because of inadequate disease surveillance and lack of good diagnostic facilities (Ameni and Roger, 1998; Ameniet al., 2001). BTB is considered endemic in Ethiopia based on abattoir inspection (Asseged et al., 2004; Girmayet al.,2012) and tuberculin test survey (Assegedet al., 2000). The present communication describes the growing significance of M.bovis in human health

\section{Etiology}

Mycobacteriun bovis is an acid fast, aerobic, non-motile, non-sporeforming, slow growing, facultative intracellular pathogen which can survive and multiply inside the macrophages and other mammalian cells (Pal, 2007). It belongs to the genus Mycobacterium of the family Mycobcateriacae. The phylogenetic analysis of the genome pathogenic Mycobacterium has shown that are except M. avium, they belong to a single genetic species: Mycobacterium tuberculosis 
complex. M. bovis belongs to the M. tuberculosis complex, which comprised of M. tuberculosis, M. bovis subspecies caprae (Pal and Boru, 2012).

\section{Epidemiology of M. bovis}

\section{Source of infection and mode of transmission}

Cattle serve as the principal reservoir of $M$. bovis. Humans can be infected with $M$. bovis where cattle are reared for milk production (Girmayet al., 2012). Organisms are excreted in the exhaled air, nasal discharge, milk, urine, vaginal and uterine discharges and discharges from open peripheral lymph nodes. Animals with gross lesions that communicate with airways, skin or intestinal lumen are obvious disseminators of infection. In the early stages of the disease before any lesions are visible, cattle may also exert viable mycobacterium in nasal and tracheal mucus. In experimentally infected cattle excretion of the organism commences about 90 days after infection (Radostitset al., 2000).Inter-human transmission of $M$. bovis is possible, but few cases have been confirmed (Acha and Szyfres, 2001).

\section{Risk Factors conductive to the spreading of $\mathrm{M}$. bovis infection in} humans

\section{Occupation}

Professional occupation involving workers such as abattoir personnel, veterinarians and laboratory technicians, animals' caretaker in zoos and those who are working in animal reservations and at national parks can also acquire the infection in due to course of their regular work (Shitaye et al., 2007).

\section{Cultures and Traditions}

In developing countries, particularly in Africa, patients'beliefs and cultural traditions are major obstacles to implement the designed tuberculosis control strategies. TB is stigmatized in many cultures and traditions, and it remains as powerful as that of HIV/ADIS, which further complicates the process of investigation by patients hiding their TB status due to discriminatory view about tuberculosis patients. Patients claimed to be unaware of the need to take a full course of treatment, and that the red color of the urine due to rifampicin treatment adversely affected their partners, resulting in sexual abstention during treatment (Ayele et al., 2004). The traditional feeding habits of consuming raw animal products in high proportion of the society of developing countries particularly in pastoralist community assumed to be major risk factors in acquiring Mycobacterium infection from animal origin (Pal, 2012). In addition to the consumption of raw milk, in some parts of developing countries due to cultural reasons, there is a habit of consuming certain raw visceral organs immediately after slaughter. This in turn may increase the chance of acquiring $M$. bovis infection. Also, during drought seasons when milk production from cow is not sufficient to provide for need of the family, pastoralist in some African country e.g.,Maasai people in Tanzania draw blood from the jugular vein of their animal and drink fresh or mixed with milk. Fresh blood is also given to ill person and to women after they have given birth (Dabron et al., 1996). Close physical contact between human and potentially infected animals is not uncommon in under developed countries. In most cases, cattle and humans in developing countries shares the same house. This, of course, increases the chance of contracting diseases such as BTB from cattle to human beings and vice versa (Cosiviet al,. 1998).

\section{Immunosuppressive Disease including HIV infection}

In many developing countries, it is very likely that cattle-to-human transmission of $M$. bovis regularly occurs. May be in few cases such transmissions may lead to self-limiting lesions, and possibly, induction of protective immunity against further infection. However, protective immunity suppressed by HIV infection and other immunosuppressive conditions, would result reactivation of tuberculosis leading to overt and progressive disease (Scanga et al., 1999). Thus, in regions with a high prevalence of HIV infection, a cycle of cattle-to-human, human- to-human and human- to- cattle transmission of disease could be established (Grange et al., 1994).

\section{Illiteracy}

It is pertinent to mention that health education should be imparted to the public about the source of infection, mode of transmission, severity of the disease, personal hygiene and preventive measures (Pal, 2007). However, like in most African countries, in Ethiopia, illiteracy is yet another unsolved problem in most rural communities in particular inability to read, write. In addition, other risk factors include lack of common knowledge among the rural people on epidemiology of various diseases including $M$. bovis infection and lack of effective prevention and control programmes (Shitayeet al., 2007).

\section{Lack of reference laboratory}

The relatively low isolation rate of $M$. bovis from HTB cases in developing countries could be partly explained by the extensive use of microscopy for confirmation of suspected cases of TB. This technique does not permit differentiation between species of mycobacterium, but the gold standard differentiation of species is based on culture methods supported with biochemical test and molecular technique. The absence of reference laboratory results in under estimation of zoonotic TB in human being (Cosiviet al., 1995).

\section{Geographic distribution}

Although bovine tuberculosis was once found worldwide, control programmes have eliminated or nearly eliminated this disease from domesticated animals in many countries. However, wild animals, which act as important reservoir of tubercle bacilli, may pose a serious threat in control and eradication programmes (Pal and Boru, 2012). Nations currently classified as tuberculosis-free include Australia, Iceland, Denmark, Sweden, Norway, Finland, Austria, Switzerland, Luxembourg, Latvia, Slovakia, Lithuania, Estonia, the Czech Republic, Canada, Singapore, Jamaica, Bar-bados and Israel. Eradication programmes are in progress in other European countries (Raghvendra et al., 2010). Although bovine tuberculosis has been eradicated from the majority of U.S. states, a few infected herds continue to be reported. From 2002 to 2013, bovine tuberculosis has been detected on numerous dairies in California (McCluskey et al., 2014), and over the period of time, a few US states may periodically lose their disease-free status. Bovine tuberculosis is still widespread in Africa, parts of Asia and some Middle East countries (Corner, 2006).Figure 1 represents WHO report showing the estimated global incidence rate of TB in 2011 .

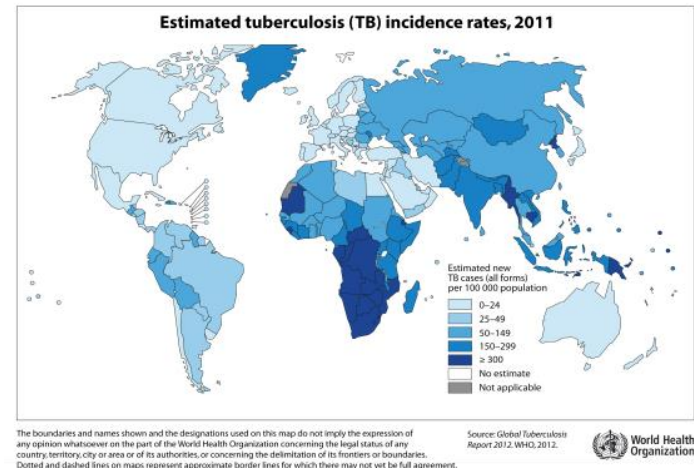

Figure 1. The WHO estimated global incidence rate of TB in 2011.

Pathogenesis

M. bovis enters the host though respiratory, alimentary, cutaneous genital routes. It may be self-limiting to fulminating disease with extensive tissue destruction. Miliary tuberculosis is the most severe form of disease with haematogenous spreading as a result of lysis of phagosomin to the macrophages. This releases bacteria into the blood from the primary foci and secondary seeding to various tissues (Anderson, 1997)

Bacilli are engulfed by alveolar macrophages in the circulation and then become established in the lymph nodes. The cellular response attempt to control the pathogen results in an accumulation of large number of phagocytes, which leads to the formation of macroscopic lesion or a tubercle. Cell mediated immunity (CMI) emerges 10-12 days after infection, triggers the release of cytokines from $\mathrm{T}$ lymphocytes. This activates the bacteriostatic effect of the macrophages and accelerates the recruitment of additional blood borne mononuclear cell into the site resulting in delayed type of hypersensitivity reaction. Necrosis results from the delayed type hypersensitivity reaction. The gross appearance of tubercle is usually firm yellow rarely a yellowish caseous necrotic material or calcified tissue is observed (Quinn et al, 2002). 


\section{Public health impact of $M$. bovis}

Global situation and trend of human tuberculosis caused by $\mathrm{M}$. bovis.

The actual incidence of TB across the globe is greatly underestimated. In 1995, WHO reported 3.3 million cases of TB whereas a more likely number is 8.8 million. Among the cases about $62 \%$ occurred in the Southeast Asian and Western Pacific regions, $16 \%$ in Sub-Saharan Africa, and $7 \%$ to $8 \%$ in each of the regions of the American, Eastern Mediterranean, and Europe. In continents, such as Africa, Asia, and South America (Caribbean countries), the prevalence of the disease was recorded at 46\%; 44\%; and $35 \%$, respectively. However, on the other hand, in industrialized nations, human TB due to $M$. bovis is relatively rare as result of proper milk pasteurization and animal TB control programme (Grange, 2001; Pal and Boru, 2012).

In 1990-1999, in the absence of effective control, global TB incidence and deaths were reached 88 million and 30 million, respectively (Dolin et al., 1994). Because of the HIV epidemic, the incidence rate of TB has been increased in Sub-Saharan Africa in the last decade and the total number of new cases doubled by the year 2000. Due to immigration particularly from countries with a high prevalence of dual HIV and TB infection, in industrialized countries, a slight increase in the incidence rate and total cases of TB has been observed in last few years (Davies PD, 2003). In 2000, approximately $40 \%$ of these HIV-attributable cases were occurring in Sub-Saharan Africa and $40 \%$ in Southeast Asia. M. tuberculosis will be largely responsible for the new TB cases and deaths, but an unknown, and potentially important, proportion will be caused by $M$. bovis (Cosivi et al., 1995).

\section{M. bovis and the pulmonary tuberculosis}

Pulmonary tuberculosis (TB) is common worldwide infection and medical and social problem causing high mortality and morbidity, perhaps especially in developing countries. In developing countries because of close physical contact between human and animals and potentially infected animals airborne transmission of $M$. bovis is occurs. In many African countries, cattle are an integral part of human social life, represent wealth and gathering them in the same house with human is common. It has been reported in Nigeria that from sputum samples of $102 \mathrm{M}$. tuberculosis complex isolate, 4 (3.9\%) were M. bovis (Idigbe et al., 1986).

In addition, developing countries working in agriculture, a significant proportion of them are at risk for bovine tuberculosis. Researched in Australia earlier suggested that TB should be considered as occupational hazard in abettor and meat industries because the disease could be transmitted to human through inhalation (Robinson et al., 1989). However, the situation may not be the same now there.

\section{M. bovis as a cause of extrapulmonary tuberculosis}

The most prevalent form of TB caused by $M$. bovis in man is extrapulmonary- a disseminated infection outside the lungs commonly involving lymphnodes, pleura, osteoarticular junctions and other areas (Figure 2). This is not because of affinity, but that is most commonly transmitted by consumption of raw milk products (Kleeberg, 1994). The mycobacterium may spread through lymphatic or haematogenous dissemination to any tract or through coughing and swallowing to the gastrointestinal tract. Bacteria may remain dormant for years at a particular site before causing disease. Since extrapulmonary TB affects virtually all organs, it has a wide variety of clinical manifestations, which causes difficulty and delay in diagnosis obtaining material for culture confirmation of extrapulmonary $\mathrm{TB}$ is much more difficult than obtaining material for culture confirmation of pulmonary TB. Extra pulmonary TB is more often diagnosed in women and young patients (Gonzalez et al., 2003).

This form of TB occurs more commonly in immunosuppressed persons and children. In those with HIV, this occurs in more than $50 \%$ of cases. Notable extrapulmonary infection sites include the pleura (in tuberculous pleurisy), the central nervous system (in tuberculous meningitis), the lymphatic system (in scrofula of the neck), the genitourinary system (in urogenital tuberculosis), and the bones and joints (in Pott's disease of the spine), among others. When it spreads to the bones, it is also known as "osseous tuberculosis". A form of osteomyelitis sometimes bursting of a tubercular abscess through skin results in tuberculous ulcer. An ulcer originating from nearby infected lymph nodes are painless, slowly enlarging and has an appearance of "wash leather". A potentially more serious, wide spread form of TB is called "disseminated" TB, commonly known as miliary tuberculosis. Miliary TB makes up about $10 \%$ of extrapulmonary cases (Jindal, 2011). The most common form of extrapulmonary tuberculosis is lymphadenitis tuberculosis with multiple differential diagnosis. Demonstration of the etiological agent by smear microscopy or culture FNA specimens is often unsuccessful. Fine needle aspirate specimens from 40 patients presenting a rural health center in south Ethiopia and diagnosed as positive for TBLN on the basis of clinical and cytological criteria were analyzed to mycobacterial DNA by PCR. Thirty (75\%) had cervical lymphadenitis and $11(27.5 \%)$ were seropostive for human immunodeficiency virus (HIV) (Kidane et al., 2002).

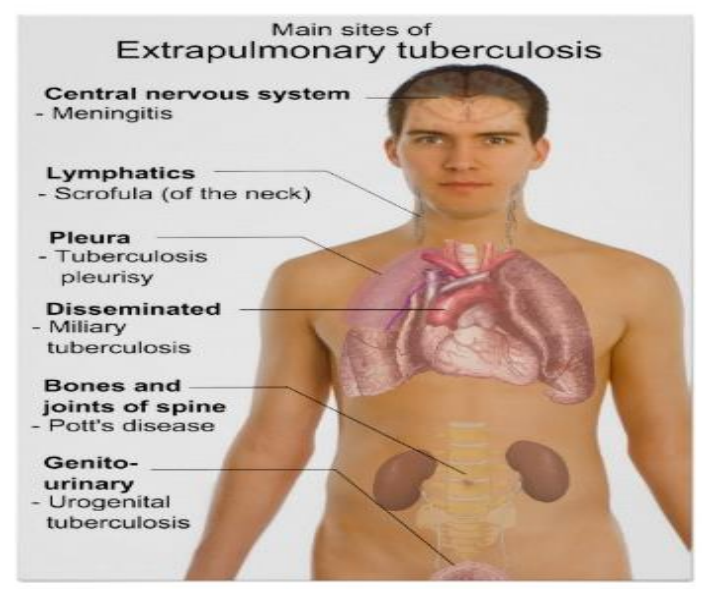

Figure 2: Main sites of Extrapulmonary tuberculosis (Hemal, 2001).

\section{Diagnosis of human Tuberculosis}

\section{Bacteriology}

The presence of acid-fast-bacilli (AFB) on a sputum smear or other specimen often indicates TB disease. Acid-fast microscopy is easy and quick, but it does not confirm a diagnosis of TB because some acid-fast-bacilli are not tuberculosis. Therefore, a culture is done on all initial samples to confirm the diagnosis. (However, a positive culture is not always necessary to begin or continue treatment for TB.) A positive culture for tuberculosis confirms the diagnosis of TB disease. Culture examinations should be completed on all specimens, regardless of AFB smear results (Harrison et al., 1994).

\section{Serology}

It has rapid diagnostic value based on the recognition of $\mathrm{IgG}$ antibody to selected Mycobacterium antigen and the use enzyme linked immunosorbent assay (ELISA) techniques have been and appear to offer promise, with sensitivity similar to that of sputum microscopy (less sensitive). In addition, there are few more serological test such as Brock TB Stat-Pak testing (Chambers et al., 2010), Animal-Side Antibody Assays (Lyashchenko et al., 2011) and monoclonal antibody (TB72) based serological test (Ivanyi et al., 1983) for detection on TB in human and animal. Serology may have its great application in case where sputum is not available and in case of extrapulmonary tuberculosis (Harrison et al., 1994).

\section{Polymerase chain reaction (PCR)}

One of the most reliable and accurate molecular method that target the detection of genes (nucleic acid) specific for a microorganism is Polymerase Chain Reaction (PCR). This nucleic acid amplification technique tests represent a major advance in the diagnosis of TB because of its high sensitivity and specificity. PCR allows amplification of genes (nucleic acid sequences) that are unique to Mycobacterium species and could be detected directly from clinical specimens. Among the genes that are commonly used for the detection of Mycobacterium are 16S rRNA genes, mmpS6 gene, $p n c \mathrm{~A}$ gene, $h u p B$ gene, antigen genes e.g., $m p b 70$ and $m p b 64$ and the insertion sequence IS6110, IS1081 (Gormleyet al., 1999; Broccolo et al., 2003; Young et al., 2005), IS900PCR (Sukumar et al., 2014). The method also offer better accuracy than AFB staining and requires very less time than cultural technique (Eisench et al., 1991). Several types PCR assays such as conventional end point analysis based PCR, multiplex-PCR and real-time PCR are available for the detection of TB. One of the major advantages of PCR is its detection 
limit, since it can detect as few as 5 to ten AFB bacilli present in clinical samples (Singh and Seth, 2002).

\section{Bronchoscopy}

A bronchoscopy is a medical procedure that allows visualization of the inside of a person's airways . The airways is called the bronchial tubes or bronchi. Bronchoscopy might be needed for specimen collection, especially if previous results have been non diagnostic and doubt exists as to the diagnosis. At other times, bronchoscopy is considered because TB is among several other diagnoses being considered. If possible, examine three spontaneous or induced sputum to exclude a diagnosis of TB disease before bronchoscopy. If possible, avoid bronchoscopy on patients with suspected or confirmed TB disease or postpone the procedure until the patient is determined to be non-infectious, by confirmation of the three negative AFB sputum smear results. Bronchial washings, brushings, and biopsy specimens may be obtained, depending on the bronchoscopy findings. Sputum collected after a bronchoscopy may also be useful for a diagnosis. A bronchoscopy should never be substituted for sputum collection, but rather used as an additional diagnostic procedure (CDC, 2005)

\section{Radiology}

A posterior-anterior chest radiograph has used to detect chest abnormalities and evaluation of tuberculosis. Lesions may appear anywhere in the lungs and may differ in size, shape, density, and cavitation. These abnormalities may suggest TB, but cannot be used to definitively diagnose TB. However, a chest radiograph may be used to rule out the possibility of pulmonary TB in a person who has had a positive reaction to a TST or TB blood test and no symptoms of disease (Harrison et al., 1994)

\section{Tuberculin test}

Most people infected with TB have no sign of the disease as the bacterium is 'sleeping' or dormant. This is called latent TB. Some people with latent TB will develop TB disease or active TB. TB disease can affect any part of the body but usually affects the lungs. The tuberculin skin test (TST) is also known as the Mantoux test. It is a skin test to detect if you have been infected with TB bacteria. It done to detect latent TB infection in a person who may have been exposed to someone diagnosed with active $\mathrm{TB}$, to obtain a baseline before employment in a health care facility or travel to a high TB risk region, and before BCG vaccination. A small amount of purified protein derived (PPD) from dead TB bacteria is injected under the top layer of the skin on the forearm using a sterile disposable needle and syringe. Please see Yang et al., (2012) for details on PPD. A small blister will appear at the site, and will disappear within 20 minutes. There may be a small amount of blood at the needle site. One should return to the clinic 3 days later to have the site assessed for any reaction. The reaction or lump is measured in millimeters. Tuberculin test is standard ante mortem test in cattle and is based on delayed type hypersensitivity. Slants of Lowenstein-Jensen medium without glycerol and with $0.4 \%$ sodium pyruvate inoculated with centrifuged deposit and incubated aerobically at 37 oc for up to 8 weeks (Pal and Boru, 2012).

\section{Prevention and control of $M$. bovis infection}

\section{Therapy}

The overall goals for treatment of tuberculosis are 1) to cure the individual patient, and 2) to minimize the transmission of tuberculosis to other persons. Thus, successful treatment of tuberculosis has benefits both for the individual patient and the community in which the patient resides. For this reason the prescribing physician, be he/she in the public or private sector, is carrying out public health function with responsibility not only for prescribing an appropriate regimen but also for successful completion of therapy. Prescribing physician responsibility for treatment completion is a fundamental principle in tuberculosis control. However, given a clear understanding of roles and responsibilities, oversight of treatment may be shared between a public health program and a private physician. It is strongly recommended that patient-centered care be the initial management strategy, regardless of the source of supervision. This strategy should always include an adherence plan that emphasizes directly observed therapy (DOT), in which patients are observed to ingest each dose of anti tuberculosis medications, to maximize the likelihood of completion of therapy. Programs utilizing DOT as the central element in a comprehensive, patient-centered approach to case management (enhanced DOT) have higher rates of treatment completion than less intensive strategies. Each patient's management plan should be individualized to incorporate measures that facilitate adherence to the drug regimen Such measures may include, for example, social service support, treatment incentives and enablers, housing assistance, referral for treatment of substance abuse, and coordination of tuberculosis services with those of other providers (CDC, 2003). Chemotherapy is entirely impractical in animals because of the high cost of treatment, the frequent recurrence of the diseases when the treatment is stopped and the possibility of the development of multidrug resistant strain of M. bovis (O'Reilly and Daborn, 1995).

\section{Sanitary prophylaxis}

In many developing countries, a test and slaughter program would be inappropriate because of lack of resources, political instability or social unacceptability of the control methods and the presence of reservoir hosts. But there are alternative strategies like programmes based on slaughter house surveillance, trace back of tuberculoses animals to herd of origin, test and isolation of animals, housing of animals separately from animals. Measures like trailing public health personnel, public education, proper hygiene practice, maintaining and reinforcing the policy of boiling or pasteurization of milk and dairy products, as well as protecting workers in animals related occupations especially animal attendants and meat industry workers need to be taken (WHO, 2004). Removal of calves at birth and feeding on either the milk of sound cows or pasteurized milk reduces the risk of infection significantly from cattle to other animals and infection of man can be avoid by pasteurization of milk (Cosivi et al., 1998;Pal,2007).

\section{Vaccination}

The vaccine that is used for the control of TB is BCG (Bacillus Calmette-Guerin). It is the only vaccine available currently for use against tuberculosis in humans (da Costa et al., 2014). It is a live attenuated strain of $M$. bovis that is not able to cause disease but induce immunity. The original strain was developed at the Pasteur Institute in Paris between 1908 and 1921 through the repeated passage by Albert Calmette and his assistant/colleague Camille Guérin. The Pasteur strain of BCG serves as the reference strain of the vaccine, and its complete genome sequence has been determined (Borsch et al., 2007). Subsequent strains have undergone further development through repeated sub culturing in many laboratories around the world. These strains are now known to differ in terms of their genome and a number of biologically intriguing phenotypes, such as those with the ability to make virulence lipids and produce antigens (Behr et al., 2000). The genealogy of BCG strain is presented in Figure 3.

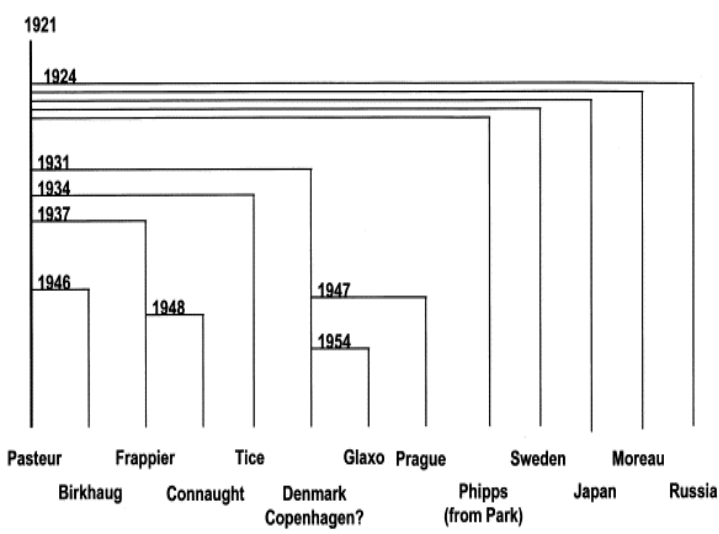

Figure 3.Genealogy of BCG strain dissemination. Vertical axis scales to time. Horizontal dimension does not scale to genetic difference (Behr and Small, 1999)

BCG is given to infants as a part of the immunization program recommended by the World Health Organization (WHO) in TB endemic area. In adults, the effectiveness of BCG has varied widely in large-scale studies. Patient vaccinated with BCG gives positive skin test (tuberculin) thus limiting the effectiveness of the PPD skin test to identify new infections. BCG is not recommended for general use in many countries of the world, particularly where the disease is not present or endemic.

Although BCG can be effective in reducing the incidence of childhood tuberculosis, particularly meningitis, it is relatively ineffective in protecting against adult tuberculosis, and does not prevent infection with the organism. Thus, BCG immunized still 
become infected with $M$. tuberculosis, can develop active tuberculosis, and can harbor the organism and reactivate later in life. It is also important to note that the BCG vaccination should not be given to woman during pregnancy and persons who are immunosuppressed particularly to the HIV positive patient. In addition to BCG, research is going on for the development of other vaccine to control $\mathrm{TB}$ including recombinant $\mathrm{BCG}$. Among them vaccine VPM1002, also called rBCG $\Delta$ ureC:hly, is currently in human clinical trials, however, much work need to done to make it effective (da Costa et al., 2014).

For cattle, in infected countries where there is no test and slaughter control scheme, BCG vaccination may be used to reduce the spread of infection in cattle, but probably will not be effective, since the vaccine does not work satisfactorily in animal (Buddle BM, 2001). The use of the test and slaughter policy to control bovine TB is economically and socially unacceptable in developing countries (OIE, 2004).

\section{Conclusions}

Mycobacterium bovis is the principal agent responsible for tuberculosis in domestic and wild mammals, but also infects humans, causing zoonotic tuberculosis. The transmission route from animals to humans and vice versa is well known and the application of fingerprinting tools facilitates analysis of the molecular epidemiology of M. bovis in animal-to-human and human-tohuman transmission (Pérez-Lago et al., 2013). Although the epidemiology of bovine tuberculosis is well-understood and effective control in elimination strategies have been known for long time, the disease is still widely distributed and neglected in most developing counties. The frequent report of human cases of lymphadenitis TB from different health centers across the country may indicate the zoonotic importance of the disease. HIV infection is the leading risk factor for tuberculosis because it promotes the progression of latent or recent infection of mycobacterium to active disease and also increases the rate of occurrence of TB. The strict meat inspection, regular tuberculin testing, proper pasteurization of milk, thorough cooking of meat, early diagnosis and prompt treatment and health education of the public will certainly help to reduce the prevalence and incidence of tuberculosis which is an international health problem. Since the disease infects both the human and animal 'One health' approach focusing strong collaboration between veterinary and human health care researchers are crucial for the prevention and control of the disease (Pérez-Lago et al., 2013). Still there are areas that need to be addressed that includes strong TB surveillance systemin rural and remote areas, vaccination of mobile populations (both animal and human) and improved public awareness for the prevention and control of TB in some part of the world particularly in Sub-Saharan African (Grater et al., 2014).

\section{References}

Acha PN and B Szyfres, 2001. In: Zoonoses and communicable diseases common to man and animals. $2^{\text {nd }}$ edition. Washington: Pan American Health Organization, Washington D.C., USA. Pp. 128-130.

Amanfu W, 2006. The situation of tuberculosis and tuberculosis control in animals of economicacal interest. Tubercul, 86: 330335. http://dx.doi.org/10.1016/j.tube.2006.01.007

Ameni G and F Roger, 1998. Study on the epidemiology of bovine tuberculosis in dairy farms (DebreZeit and Zeway, Ethiopia). In: Proceedings of the $12^{\text {th }}$ Conference of the Ethiopia Veterinary Association (EVA), Addis Ababa, Ethiopia. Pp. 13-19.

Ameni G, A Regassa, TKassa and G Meedhin, 2001. Ssurvey on bovin tuberculosis and its public implication to cattle raising families in WolaitaSoddo, Suthern Ethiopia. J Anim Prod, 55-62.

Anderson P, 1997: A review: Host response and antigens involved in protective immunity to Mycobacterium tuberculosis. Scan. J Immunol,.45:115-131.http://dx.doi.org/10.1046/j.13653083.1997.d01-380.x

Asseged B, A Lubke-Becker, E Lemma, K Tadele and S Britton, 2000. Bovine TB: a cross-sectional and epidemiological study in and around Addis Ababa. Bull. Anim Health Prod Afr, 48:7180.

Ayele WY, SD Neil, J Zinsstag, MG Weissand I Pavlik, 2004. Bovine tuberculosis. An old disease but a new threat to Africa. Int. J Tubercul Lung Dis,.8: 924-937.

Behr MA and PM Small, 1999. A historical and molecular phylogeny of BCG strains. Vaccine, 17(7-8):915-922.

Behr MA, BG Schroeder, JN Brinkman, RA Slayden and CE Barry, 2000. A point mutating in the mma3 gene is responsible for impaired methoxymycolic acid production in Mycobacterium bovis BCG strains obtained after 1927. J Bacteriology, 182: 3394-99. http://dx.doi.org/10.1128/JB.182.12.3394-3399.2000

Brosch R, SV Gordon and T Garnier, 2007. Genome plasticity of BCG and impact on vaccine efficacy. Proc. Nat. Acad. Sci. U S A, 104: 5596-601.http://dx.doi.org/10.1073/pnas.0700869104

Buddle BM, 2001. Vaccination of cattle against Mycobacterium bovis. Tubercul. (Edinb). 81(1-2): 125-132.

CDC, 2003. Morbidity and Mortality Weekly Report June 20, 2003 / Vol.52/ No.RR-11.

CDC, 2005.Controlling tuberculosis in the United States: Recommendations from the American Thoracic Society, CDC, and the Infectious Diseases Society of America. MMWR 54 (No.RR-12).

Chambers MA, KP Lyashchenko, R Greenwald, J Esfandiari, E James, L Barker, J Jones, G Watkins and S Rolfe, 2010. Evaluation of a rapid serological test for the determination of Mycobacterium bovis infection in badgers (Melesmeles) found dead. Clin Vaccin Immunol, 17: 408-411. http://dx.doi.org/10.1128/CVI.00424-09

Corbett EL, CJ Watt, N Walker, BG Maher, MC Raviglione and C Dye, 2003.The growing burden of tuberculosis, global trends and interactions with the HIV epidemic. Arch Int Med.163:1009-1021. http://dx.doi.org/10.1001/archinte.163.9. 1009

Corner LA, 2006. The role of wild animal populations in the epidemiology of tuberculosis in domestic animals: How to assess the risk. Vet Microbiol, 112: 303-312. http://dx.doi.org/ 10.1016/j.vetmic.2005.11.015

Cosivi O, FK Meslin, CJ Dabron and JM Grange,1995.The Epidemiology of M.bovis in infections in animals and humans, with particular reference to Africa. OIE. Scient Tech Rev,.14: 733-746.

Cosivi O, JM Grange, CJ Daborn, MC Ravislione, D Causins and RA Robison, 1998.Zoonotic tuberculosis due to Mycobacterium bovis in developing countries. Emerg. Infect. Diseas.40:1-14.

Dabron CJ, JM Grange and RR Kazwala, 1996. The bovine tuberculosis cycle an African perspective. J Appl Bacteriol, 81: 27-32.

Davies PD, 2003. The world-wide increase in tuberculosis: how demographic changes, HIV infection and increasing numbers in poverty are increasing tuberculosis. Annals Med, 35(4):235-243.

Dolin PJ, MC Raviglione and AKochi,1994. Global tuberculosis incidence and mortality during 1990-2000. Bull World Health Org,.72:213-20

Dye C, S Scheele, P Dalin, V Pathania andMC Raviglione,1999. Consensus statement.Global burden of tuberculosis, estimated incidence, prevalence, and mortality by county. WHO global surveillance and monitoring project. J Ame Med Assoc, 282:677-686. http://dx.doi.org/10.1001/jama.282.7.677

Eisenach KD, MD Sifford, JH Bates and JT Crawford, 1991. Detection of Mycobacterium tuberculosis in sputum samples using a polymerase chain reaction. Am Rev Resp Dis, 144: 1160-1163.http://dx.doi.org/10.1164/ajrccm/144.5.1160

Flynn JL, 2004. Review: Immunology of tuberculosis and implication in vaccine development. Tubercul, 84: 93-101

Girmay G, M Pal, D Deneke, G Weldesilasse and Y Eqar, 2012. Prevalence and public health importance of bovine tuberculosis in and around Mekelle town, Ethiopian Int J Livest Res, 2:180188.http://dx.doi.org/10.1016/j.rvsc.2014.04.010

Gonzalez OY, G Adams, LD Teeter, TT Bui, JM Musser and EA Graviss, 2003. Extra-pulmonary manifestations in a large metropolitan area with a low incidence of tuberculosis. Int $\mathbf{J}$ Tubecrul Lung Dis, 7:1178-1185.

Grange JM, 2001. Mycobacterium tuberculosis infection in human beings. Tubercul, 81: 71-77.http://dx.doi.org/10.1054/ tube. 2000.0263

Grange JM, C Daborn and O Cosivi,1994. HIV-related tuberculosis due to Mycobacterium bovis. Vet Microbiol, 137-151. http://dx. doi.org/10.1016/0378-1135(94)90052-3

Greter H, Jean-Richard V, Crump L, Béchir M, Alfaroukh IO, Schelling E, Bonfoh B, Zinsstag J, 2014. The benefits of 'One Health' for pastoralists in Africa. Onderstepoort J Vet Res, Apr 23;81(2):E1-3. doi: 10.4102/ojvr.v81i2.726.

Harrison JR, E Braunwald, JD Wilson, JB Mortin, AS Fauci and DL Kasper,1994. Diseases caused by Mycobacterium. Principles of Internal Medicine, $13^{\text {th }}$ ed. Mc GrawHill.Inc. United States of America. Pp.710-711.

Hemal AK, 2001.Genitourinary tuberculosis. In: Sharma SK, Mohan A, editors. Tuberculosis New Delhi: Jaypee Brothers Medical Publications. Pp. 325-327. 
Idigbe E, CE AnyiwoandDI Onwujekwe, 1986. Human pulmonary infections with bovine and atypical Mycobacterium in Lagos, Nigeria. J Trop Med Hyg,.89:143-148

Ivanyi J, E Krambovitis and M Keen, 1983. Evaluation of a monoclonal antibody (TB72) based serological test for tuberculosis. Clin Exp Immunol, 54: 337-345.

Jindal SK, 2011. Textbook of Pulmonary and Critical Care Medicine. New Delhi: Jaypee Brothers Medical Publishers. Pp. 525-549.

JouR, WL HuangandCY Chiang,2008. Human tuberculosis caused, by Mycobacterium bovis in Taiwan. Emerg Infect Dis, 14:515517.http://dx.doi.org/10.3201/eid1403.070058

Kidane D, JO Olonbo, A Habte, Y Nesse, A Aseffa, G Abate, MA Yassin, KHBereda and M Arboe, 2002. Identification of the causative organim of tuberculous lymphadenitis in Ethiopia by PCR. J Clin Microbiol, 40:4230-4234.

Kleeberk, H.H. 1994. Tthe Tuberculin test in cattle. J African Vet Med Assoc, 31: 213-225.

Lyashchenko KP, R Greenwald, J Esfandiari, S Rhodes, G Dean, R Rua-Domenech, M Meylan, $\mathrm{H}$ Vordermeier and Zanolari P, 2011. Diagnostic value of Animal-Side Antibody Assays for rapid detection of Mycobacterium bovis or Mycobacterium microti infection in South American Camelids. Clin Vaccin Immunol, 18: 2143-2147. http://dx.doi.org/10.1128/CVI.0538611

McCluskey, B, Lombard, J. Strunk, S. Nelson, D. Robbe-Austerman, S. Naugle and Edmondson A, 2014. Mycobacterium bovis in California dairies: A case series of 2002-2013 outbreaks. Prev Vet Med,. Aug 1;115(3-4):205-16. doi: 10.1016/j.prevetmed. 2014.04.010. Epub 2014 Apr 28.

O'Reilly L Mand and CJ Dabon, 1995. The epidemiology of Mycobacterium bovis infections in animals and man. A review. Tubercul Lung Dis, 1:1-46.http://dx.doi.org/10.1016/0962-8479 (95) $90591-X$

OIE, 2004. Diagnosis of bovine tuberculosis. In: manual of diagnostic tests and vaccine for terrestrial animals. $3^{\text {rd }}$ Edition. OIE, Paris, France.

Pal M, 2005. Importance of zoonoses in public health. Indian $\mathbf{J}$ Animal Sci,75:586-591.

Pal M, 2007. Zoonoses, $2^{\text {nd }}$ ed., Satyam Publishers, Jaipur, India. Pp. 145-147.

Pal M, 2012. Public health hazards due to consumption of raw milk. The Ethiopian Herald. March 14, 2012. Pp.10

Pal Mand and BG Boru, 2012. Zoonotic significance of Mycobacterium bovis. J Natural Hist, 8: 86-89.

PalM, 2007. Zoonoses. $2^{\text {nd }}$ Edition.Satyam Publishers. Jaipur, India.

Pérez-Lago L, Y Navarro and D García-de-Viedma, 2013. Current knowledge and pending challenges in zoonosis caused by
Mycobacterium bovis: A review. Res in Vet Sci, Dec 1. pii: S0034-5288(13)00370-6. doi: 10.1016/j.rvsc.2013.11.008.

Quinn PJ, ME Carter, GR Markey and GR Carter, 2002. Clinical Veterinary Microbiology. Mosby International Publishers, Pp. 156-169.

Radostits OM, CC Gay, DC Blood and KW Hinchelift, 2000. Veterinary Medicine, $9^{\text {th }}$ ed. Harcourt Publishers, London, Pp. 909-918.

Raghvendra, Sharma V, GS Arya, M Hedaytullah, S Tyagi, R Kataria, AP Pachpute and SJ Sharma. 2010. Clinical aspects of bovine tuberculosis- a chronic bacterial disease of cattle: an overview. Int J Phytopharmacol, 1(2): 114-118.

Robinson P, D Morris and R Anti, 1989.Mycobacterium bovis as an occupational hazard in abattoir worker. Australian New Zealand J Med, 19: 409-410. http://dx.doi.org/10.1111/j.1445-5994. 1989.tb00289.x

Scanga CA, VP Mohan, H Joseph, K Yu, J Chan and JL Flynn, 1999. Reactivation of latent tuberculosis: variations on the Cornell murine model. Infect Immun. 67:4531-4538.

Sequeira MD, V Ritaco and IN Kantor, 2005. In: Thoen, O., Gilsdorf, M.J., Steele, J., (Eds.), Mycobacterium bovis infection in animals and humans. Blackwell Publishing, Ames, USA,Pp. 315-318.

Shitaye JE, W Tsegaye and I Pavlik, 2007. Bovine tuberculosis infection in animal and human populations in Ethiopia. Review Vet Med, 52:317-332.

Singh UB and P Seth, 2002. PCR diagnosis of tuberculosis: experience in India. Indian J Pediatric, 10: S20-S24.

Sukumar B, L Gunaseelan, K Porteen and K Prabu, 2014. Goat milk as a non-invasive sample for confirmation of Mycobacterium avium subspecies paratuberculosis by IS900 PCR. J Adv Vet Anim Res, 1(3): 136-139. http://dx.doi.org/10.5455/javar. 2014.a25

WHO, 1997. Report of the WHO working group on zoonotic tuberculosis (Mycobacterium bovis) with the participation of FAO, Maize, Germany. World Health Organization, Geneva.

WHO, 2004. Global Tuberculosis control: Surveillance, planning and financing. WHO Report. World Health Organization, Geneva, Switzerland.

WHO, 2011. World Health Organization. Global tuberculosis control: WHO Report 2011. Geneva: The Organization; 2011.

Yang H, NA Kruh-Garcia and KM Dobos, 2012. Purified protein derivatives of tuberculin--past, present, and future. FEMS Immunol Med Microbiol, 66(3): 273-280. doi: 10.1111/j.1574695X.2012.01002.x. Epub 2012 Aug 1.http://dx.doi.org/10. 1128/AEM.71.4.1946-1952.2005 